\title{
RETRATOS DE ARTISTAS QUANDO DAS LEITURAS E DAS ESCRITAS
}

Antonio Rodrigues Belon ${ }^{1}$

\section{INTRODUÇÃO}

Inicialmente cumpre destacar dois pontos.

As entrevistas a seguir correspondem a uma linha teórica e de trabalho do professor já consolidada - este o primeiro ponto. O segundo decorre da sistemática de investigação, do envolvimento dos alunos, dos grupos de pesquisa, das disciplinas de pós-graduação.

De outro ponto de vista duas fases entram em consideração.

$\mathrm{Na}$ primeira delas o número 14 da Revista Eletrônica Literatura e Autoritarismo vale recuperar a informação sobre uma contribuição do hoje falecido escritor Wilson Bueno em duplicidade: a primeira através da tradução para o Francenglish de um texto que seria publicado pela Oxford Press University - AQUIDAUANA AFTERNOON - e a segunda por meio da entrevista que o escritor concedeu: WILSON BUENO, O POETA DE CURTIBA: UM PEQUENO RETRATO EM FORMA DE ENTREVISTA DO CANTOR DAS TARDES MELANCÓLICAS DA FLORESTA. Isto ocorreu em 2009.

Na segunda, no número 16, novamente da Revista Eletrônica Literatura e Autoritarismo, de 2010, NO RETRATO DO ARTISTA, OS RIGORES E A DELICADEZA DE ABRIL: JOÃO ANZANELLO CARRASCOZA é a entrevista com o escritor João Anzanello Carrascoza por Antônio Rodrigues Belon e Michela Mitiko Kato Meneses de Souza, inaugurando a prática de trabalho

\footnotetext{
1 . Professor colaborador do Programa de Pós-Graduação, Mestrado em Letras, do campus de Três Lagoas da Universidade Federal de Mato Grosso do Sul. Professor pesquisador colaborador sênior e pós-doutorando do Programa de Pós-Graduação em Literatura, do Instituto de Letras, da Universidade de Brasília.
} 
conjunto entre docente e discente no planejamento e execução das entrevistas, o destaque.

As entrevistas sempre se antecipam por um pequeno estudo biográfico sobre o escritor, moldura do retrato do artista constituído por perguntas e respostas.

As entrevistas, inéditas, do segundo semestre de 2011, foram realizadas, no bojo de atividades acadêmicas no Programa de Pós-Graduação, Mestrado em Letras, do câmpus de Três Lagoas, da Universidade Federal de Mato Grosso do Sul, pelo professor e alunos do programa. As notas de rodapé asseguram os pormenores da identificação dos entrevistadores.

Do entrelaçamento das vozes dos entrevistadores e dos entrevistados os retratos dos artistas ganham forma. Falam os entrevistadores - Antonio Rodrigues Belon, Bianca Estevam Veloso Ferreira, Édilis Michelli dos Santos Cunha Richard Quintas, Fabrina Martinez de Souza e Vanderlei de Souza, e os entrevistados, Ana Paula Maia, Andréa Del Fuego, Daniel Galera e Marcelo Benvenutti. 


\section{UMA ESCRITORA NÃO DANÇA MAIS OU OS PASSARINHOS E A ORNITOLOGIA}

Antonio Rodrigues Belon ${ }^{2}$ Édilis Michelli dos Santos Cunha Richard Quintas ${ }^{3}$

Na apresentação breve de Andréa Del Fuego o registro do local e do ano de nascimento é importante. Ela é de 1975, de São Paulo, a capital homônima do Estado e maior cidade do Brasil. Formada em publicidade, produziu duas curtas-metragens.

Escreveu e publicou Minto enquanto posso (contos, 2005), Nego tudo (contos, 2005), Engano seu (contos, 2007), Sociedade da Caveira de Cristal (romance, 2008), Quase caio (crônicas, 2008), Nego fogo (contos, 2009), Irmãs de pelúcia (infantil, 2010), Os Malaquias (romance, 2010) e O implicante, conto baseado na trilha sonora do filme Blade Runner, digital (2007). Participou de inúmeras antologias, no Brasil e no exterior. Recebeu os prêmios de Literatura Para Todos do Ministério da Educação (2008), São Paulo de Literatura (2011) e José Saramago (2011). Mantém o endereço eletrônico www.andreadelfuego.wordpress.com.

Por ela temas de rica diversificação configuram uma entrevista.

A história tem fiadores, a literatura não. Fala de uma continuidade lógica das redes sociais, da mídia e da literatura. Da pergunta pela autonomia estética resulta um delicioso mistério posto pela escritora ao tomar para si a questão. Assim como o passarinho está para o ornitólogo, a escritora - os escritores estaria para a crítica, a teoria, a historiografia, os estudos literários, o leitorado.

Nas palavras de Andréa Del Fuego, todo um programa de trabalho estético: "a matéria-prima se origina da memória e da experiência. Afinal, o pensamento é uma experiência, inclusive física, não tem tanta transcendência quanto gostaríamos." Uma poética irmã da lucidez.

A literatura interpreta e é realidade; não seria imprescindível. Menciona os apartamentos, os espaços urbanos, predominantes e outros cenários no atendimento de suas exigências de construção, em geral, e da elaboração de

\footnotetext{
2 Identificado na nota 1.

3 Aluna especial do Programa de Pós-Graduação, Mestrado em Letras, do campus de Três Lagoas da Universidade Federal de Mato Grosso do Sul.
} 
personagens. Andréa Del Fuego ao encontro do prazer vai dos contos ao romance. Um projeto caminha dos leitores mais próximos aos mais distantes. A inovação se dá na lógica interna da literatura, independente dos suportes de ponta do tipo internet. Escrever é trabalhar; é quebrar pedras. A literatura formadora, para além do consumo, é politicamente relevante. A escrita feminina tem o seu lugar nas livrarias, na sociedade e na história; aboliu barreiras. O público infantil e o juvenil constituem uma referência (Irmãs de pelúcia e Sociedade da Caveira de Cristal). O Prêmio Saramago decorre do trabalho. A premiação funciona como um marco para a depuração. Isto tudo entra no denso retrato de uma escritora.

Mas haveria duplicidade das Andréas: a formal e literária, a Andréa Del Fuego, não real.

O que quer a escritora? Anseia por afiar a escrita; receia perder o gume na falta de tempo. A água que o passarinho bebe: a fotografia inspira a narrativa da autora.

A brincadeira começou; agora não dá mais para parar de escrever. Brincadeira? $\mathrm{Na}$ literatura a seriedade, na dança a brincadeira: não há intercâmbios, permutas, entre elas? É possível dançar como se escrevesse? É possível escrever como se dançasse?

Opine sobre as relações entre a literatura e a história.

Andréa Del Fuego - A literatura, apesar da intenção de transgredir seu tempo, deixa surgir um registro de sua época. Nesse sentido, as duas são irmãs, uma vez que a história pode ser contada de tantas formas que pode mesmo beirar a ficção. Elas se diferenciam em outra questão, enquanto na história uma recente descoberta ou escavação pode mudar a narrativa histórica, na literatura não há um fiador do fato, a narrativa se sustenta por si, ela existe por si, se prova por si, não há documento descoberto que possa modificar sua realidade.

Escrever livros e blogues, atuar como comentarista de programas de televisão, multiplicados nas mídias virtuais, é um rol de atividades logicamente articuladas?

Andréa Del Fuego - Com o compartilhamento dentro das redes sociais, há mesmo uma lógica entre as atividades que envolvem a literatura, contando aí 
os blogues e os comentários para a televisão, por exemplo. Na verdade, mesmo atividades díspares ficariam ligadas por alguma lógica que o próprio compartilhamento acaba explicitando ou mesmo criando. Mas escrever livros é uma atividade interna, solitária de verdade, sem janelas abertas, com concentração de cirurgião. O blogue e a televisão são expressões imediatas, sem o amadurecimento que o tempo traz, no caso da escrita.

Como as realidades do mundo e do ser, individual e socialmente, nas suas configurações históricas, tornam-se, na narrativa, componentes de uma estrutura estética, permitindo o estudo da autonomia do texto literário?

Andréa Del Fuego - Esse é o mistério da literatura, que na escrita é vivido sem ser desvendado. Como é possível a autonomia de um texto literário? Essa pergunta também é minha, é possível que o ser no tempo e na história se liberte das concessões que o tempo pede, para tornar-se universal, a ponto de conversar com um tempo futuro, que não se fez ainda? Quando lemos grandes obras, elas nos parecem contemporâneas, ainda que escritas quando nem éramos um espermatozóide. Ao ler uma grande obra, não há dúvida de que o ser se desdobra em estética, algo entre a moral e a teoria do conhecimento. Mas esse deslocamento de um campo para outro é um delicioso mistério.

Do ponto de vista da realimentação de sua escrita em fluxo contínuo, qual o papel da relação com as expressões literárias, especificamente, e culturais, de um modo geral, no panorama de início do século XXI - no seu modo de ver? Você se insere em tradições mais distantes - além dessas?

Andréa Del Fuego - Como diz o ótimo escritor Evandro Affonso Ferreira, "eu sou passarinho, não ornitólogo". Adoro essa frase, e não porque ela isenta o escritor de pensar a própria obra, mas porque coloca honestamente o ponto de vista real do autor, o centro que, no lugar de dar uma visão privilegiada, na verdade a distorce. Nesse caso, nem me atrevo a definir em que tradição me encaixo, se é que meu trabalho seja consistente a ponto de ter algum lugar. Em termos de realimentação da escrita, de influências, as expressões culturais mais fortes não vêm da literatura, mas da escuta diária, do movimento de corpos na cidade, do trânsito próprio de sensações e ações. 
Os materiais não literários tornam-se literários?A escrita literária se constrói a partir do mundo? As esferas históricas, sociais, políticas e estéticas imbricamse?

Andréa Del Fuego - Concordo, a matéria-prima se origina da memória e da experiência. Afinal, o pensamento é uma experiência, inclusive física, não tem tanta transcendência quanto gostaríamos.

A literatura é uma forma imprescindível de sentir e de interpretar a realidade originária?

Andréa Del Fuego - Não é imprescindível, mas é uma forma de interpretar a realidade. A questão da arte como cópia do modelo é tão antiga e ainda nos perguntamos sobre essa transferência do real para a imitação. De alguma maneira, a literatura tem uma carga real por si, uma realidade em si mesma, ainda que apoiada no verossímil.

No quadro histórico da ficção brasileira hoje se fala muito nas tendências, nas gerações, nas antologias (especialmente Geração zero zero, organizada por Nelson de 10Oiveira, publicada em 2011) nos registros entre o memorialista, o realista, o metafísico, o escatológico, o fantástico e o satírico, nos seus autores representativos, mas considera-se, sobretudo, a urbanização do imaginário. Onde entra no quadro da contemporaneidade a literatura de Andréa Del Fuego? Como vê a ficção brasileira hoje?

Andréa Del Fuego - A urbanização do imaginário me parece incontornável, no entanto, essa urbanização pode ser deslocada para outros cenários. Os ciclos naturais que mal visualizamos nas cidades também podem estar camuflados ou acelerados por um personagem que assim o queira em cenário rural ou mesmo espacial, "a urbanidade" estará lá. No meu caso, o primeiro romance se dá em cenário rural, mas o romance que estou terminando acontece no centro de uma grande cidade, não se trata de uma escolha, mas de uma história que surge com suas próprias necessidades narrativas. Hoje, nossa literatura é escrita por muitas vozes, são tantas, que não há espaço para a sua manifestação completa, os estilos se diferem, as temáticas, ainda que quase todos estejam escrevendo dentro de apartamentos.

A sua literatura se constitui mais de contos que de romances. Onde está o seu maior prazer? Onde você sente mais o peso da responsabilidade? 
Andréa Del Fuego - Os contos foram um ponto de partida para o primeiro romance, é como se eu estivesse neles apenas amolando a faca. O maior prazer está no romance, na longa narrativa, justamente pelo peso da responsabilidade, a montanha a subir é maior, mais íngreme, e exige maior entrega. Nesse caso, pelo menos comigo, mergulhei na linguagem na feitura do romance, mais do que na feitura de contos.

Qual o seu público? Os leitores da internet, os das universidades, os das livrarias?

Andréa Del Fuego - Ainda não sei, até aqui apenas percebi que meus leitores estão muito próximos, são escritores ou leitores que querem escrever. Somos muito poucos. Com o Prêmio José Saramago, sonho em aumentar esse raio de alcance. O livro sairá em Portugal, Argentina e Alemanha, mal posso esperar para conhecer esses futuros leitores, que estão ainda mais distantes de nosso paladar literário.

A literatura na internet inova?

Andréa Del Fuego - Não, a literatura entra em refluxo e em outros momentos rebenta conforme alguma lógica interna que não sei precisar. Não será a internet que a inovará. Agora, a internet criou uma leitura mais rápida, e a leitura é parte da literatura, nesse caso também pode influenciar a escrita já que é nossa realidade, essa de onde partimos para escrever.

Provocativamente: criacionismo, ou trabalho? Qual a sua estrada?

Andréa Del Fuego - Trabalho árduo, de quebrar pedra. Não foi em transe que escrevi melhor ou pior, mas foi trabalhando e retrabalhando texto que vi alguma melhora no trabalho.

Se a literatura fosse uma ferramenta para a ação... A política é importante para a literatura? Para a arte? Em que sentido?

Andréa Del Fuego - A política trata das normas da cidade, da vida em comum, se a leitura é um hábito que supostamente aumenta a experiência mental, ela está ligada não ao entretenimento, mas à educação como instrumento que molda uma natureza plástica do homem para melhor viver em coletividade. É nesse sentido que a política é importante, reconhecendo a literatura como formadora e não apenas consumo. 
O que você pensa sobre o espaço que as escritoras femininas têm atualmente, e/ou sobre a escrita feminina?

Andréa Del Fuego - Acredito que não haja mais essa barreira, um lugar na livraria distinto, uma estante para escrita feminina e outra para escrita masculina. Não há mais desculpa para que a mulher não escreva ou para que um homem não leia uma mulher. A questão, na realidade, estará totalmente superada se não nos perguntarmos mais por isso, mas escrevermos de forma árdua, sem desejar um privilegio de princesa.

Qual a faixa etária de publico que você acredita atingir mais, por quê?

Andréa Del Fuego - Tenho livros juvenis e um deles, o Sociedade da Caveira de Cristal, é muito adotado em escolas. Há comunidades virtuais feitas por adolescentes que comentam o livro, nunca vi leitores mais entregues do que os adolescentes. É um leitor exigente e sincero.

Você ganhou recentemente o prêmio Saramago, para alcançar esse resultado você traçou objetivos, como foi o trajeto e você atribui esse resultado a quê?

Andréa Del Fuego - Não tracei outro trajeto que não fosse escrever e ser lida e contar com a sorte. Publico há quase 10 anos e já senti muita frustração, mas nunca a ponto de desistir, e é exatamente na frustração que se mede a força da vontade. Atribuo o resultado à teimosia e ao trabalho que nunca deixei de fazer.

Qual a importância deste prêmio para sua carreira. O que irá ajudá-la? Você acredita que irá atrair a atenção de outras editoras após esse marco em sua carreira?

Andréa Del Fuego - A importância é enorme já na minha disposição em escrever mais e também de forma mais lenta e depurada. O prêmio atraiu algumas editoras, inclusive fora do país. O que está fazendo uma grande diferença, nesse sentido, é a agente literária Nicole Witt das Agência MertinLitag, trata-se de uma agente alemã muito séria que me procurou antes do prêmio, ela é muito respeitosa com o autor e com o livro e faz um trabalho que nunca vi igual. É um marco, com certeza, mas o pés continuam um na frente do outro.

Hoje você é simplesmente Andrea Del Fuego ou você ainda é Andrea Fátima dos Santos, existe alguma diferença entre uma e outra? Andrea Del Fuego é 
mais uma personagem ou você realmente vive Andrea Del Fuego, como você lida com essa questão?

Andréa Del Fuego - Não chega a ser uma questão, o pseudônimo foi ficando, fui esquecendo de esquecê-lo. Mas confesso que adoro ter outro nome no RG, como se dois nomes me dessem dois documentos, um na esfera íntima, outro na rua. Claro que nada disso se relaciona com qualquer dupla personalidade, sou equilibrada o bastante para não brincar de ser personagem no cotidiano.

Quais são seus maiores anseios e receios?

Andréa Del Fuego - Entre os anseios atuais estão manter a escrita sempre afiada, manter as facas amoladas. Entre os receios estão não ter tempo para aprimorar os próximos textos que virão, medo de que algo me tire esse tempo. Um dos autores que compõe o Livro Geração zero zero diz que sua inspiração vem de uma frase e a sua inspiração se dá através do quê?

Andréa Del Fuego - Vem de fotografia, pode ser da memória ou um frame de um filme ou da própria em revistas e livros de fotografia. A fotografia não deixa de ser uma frase.

Existe alguma questão que você gostaria de responder, mas que nunca a fizeram? Caso tenha diga qual seria a questão e a responda.

Andréa Del Fuego - Por que não desiste de escrever? Agora não, agora é que a brincadeira começou.

Esqueceram de perguntar; ou não quiseram; ou não souberam... Hoje o que Andréa Del Fuego perguntaria a Andréa Del Fuego?

Andréa Del Fuego - Por que ficou tão séria? Por que não dança mais? 


\title{
2. LOCAL E UNIVERSAL: MARCELO BENVENUTTI, UM CONTISTA SIMPLESMENTE
}

\author{
Antonio Rodrigues Belon ${ }^{4}$ \\ Vanderlei de Souza ${ }^{5}$
}

Marcelo Benvenutti é um porto-alegrense, desde 1970. Publicou Vidas cegas (2002), Livro laranja (2003), O ovo escocês (2004), Manual do fantasma amador (2005) e Arquivo morto (2008). Todos os livros entram na rubrica contos e na geração zero zero (de 2000 a 2009). Um gênero de textos literários e um tempo de surgimento para eles e o escritor ficam evidentes.

Uma literatura em busca da ultrapassagem das fronteiras de seu tempo; uma literatura que se quer anti; e de combate. Explicita uma proposta de ser pop (seja lá isto o que for; vale escutar atentamente o escritor). Quer forçar barreiras.

Marcelo Benvenutti reivindica para si uma objetividade. A de seus contos largados no mundo como filhos crescidos. A de ser contista simplesmente. A do local em identidade com o universal.

As histórias, escritas, vivem entre descobertas: nascem de descobertas, dão nascimento a outras.

Marcelo Benvenutti assume as brincadeiras com a idéia de cânone, mas não perde a dimensão da necessidade de ganhar a vida. Isto já não é brincadeira. Sabe da relevância de suas relações com as editoras, cultivando um equilibrio de quem aponta problemas, mas não vive a se lamentar.

De instinto provocador quer uma crítica contemporânea, do tempo presente; a existência da crítica é sempre melhor que a ausência dela. Nega importância ao seu trabalho em área de formação distante da literatura: vale a vida na sua diversidade de áreas de atuação. A vida é uma grande sopa a alimentar o escritor e sua escrita: a literatura é visão e delírio. Banha-se de ser inteiro na políica e na religião por não negar a vida. Elabora as vozes de seus instrumentos e as da vida em ebulição e mistura.

\footnotetext{
4 Identificado na nota 1.

5 Aluno especial do Programa de Pós-Graduação, Mestrado em Letras, da Universidade Federal de Mato Grosso do Sul.
} 
Marcelo Benvenutti em espanhol, que descobertas ele traria? Um retrato do artista quando no jogo das perguntas e respostas.

No http://uww.escritorpop.blogspot.com/ damos de cara com um manifesto com o título de Escritor Pop. Você articula a época da internet com a dos manifestos?

Marcelo Benvenutti - Não. É quase um anti-manifesto. A literatura tem que sair dos guetos que muitas vezes os próprios escritores criam. Resumindo, Literatura Pop é isso. Ultrapassar a fronteira que separa a maioria dos escritos de seus possíveis leitores.

Quais são os limites da literatura pop?

Marcelo Benvenutti - Sem limites. O pop não tem e nem deve ter limites. Obviamente, com o tempo, terá um limite. O limite do alcance cultural dos leitores. Nesse sentido é uma forçada de barra para que a literatura vença as barreiras da frágil educação da população brasileira.

Como as realidades do mundo e do ser, individual e socialmente, nas suas configurações históricas, tornam-se, na narrativa, componentes de uma estrutura estética, permitindo o estudo da autonomia do texto literário?

Marcelo Benvenutti - Acredito que tudo que tu colocou na pergunta fica tão subjetivo pra mim que prefiro nem pensar na resposta. Nem na estrutura estética, que seria a maior preocupação. Deixo rolar. Quando termino o texto, reviso algumas vezes, leio uma última vez e depois o conto que se vire. Ou o leitor. Sou totalmente irresponsável nesse sentido.

Se um escritor é católico, mentiroso, colorado, cervejista, pai do Lorenzo, parece uma personagem e tanto. O que mais Marcelo Benvenutti é na perspectiva literária?

Marcelo Benvenutti - Atualmente sou só um contista tentando pagar suas contas e, sem tempo pra contar histórias, tento pensar em como escrever um romance já parado faz algum tempo. Não tenho muitas esperanças de que mude algo a curto prazo. Me resta o tempo.

Marcelo Benvenutti, porto-alegrense, nascido em 1970, vive fora do eixo Rio/São Paulo: isto tem implicações na sua literatura? 
Marcelo Benvenutti - Tem e não deveria ter. Por ser porto-alegrense e totalmente incrustado na cultura local, ou pelo menos no meu gueto roqueiro de Porto Alegre, pode parecer que os textos são datados ou regionalistas. Mas não são. Ou não deveriam ser. A qualidade de um conto ou um romance é que o classificam e não onde a história se passa ou as peculiaridades locais. $O$ local é universal.

Atualmente você se dedica a escrever um romance? A sua literatura se constitui basicamente de contos. Onde está o seu maior prazer? Onde você sente mais o peso da responsabilidade?

Marcelo Benvenutti - O prazer está em descobrir a história e a história descobre o resto. A responsabilidade, no meu caso, é nenhuma. É preciso uma certa, grande, dose de inconsequência. Se não for assim, pra que escrever?

E se a brincadeira der certo, ou der errado, e se o escritor pop tornar-se canônico?

Marcelo Benvenutti - Tomara que eu ganhe pelo menos algum pra pagar as contas do supermercado.

As suas obras foram publicadas pela Kafka Edições. Como consideraria suas relações com as editoras?

Marcelo Benvenutti - Boas. No sentido de liberdade, ótimas. Como as editoras são pequenas, ou "independentes", não existe uma pressão sobre o autor em se limitar em temas ou controlar seus instintos. De resto, como todas as editoras pequenas, a distribuição é irregular pelo próprio tamanho das mesmas, logo, mesmo que bem divulgado, o livro não tem alcance mais numeroso de leitores por não estar no ponto de venda mais privilegiado.

O tom coloquial e provocativo do uww.escritorpop.blogspot.com/constitui um dos elementos fundamentais na sua prática da escrita literária?

Marcelo Benvenutti - Sempre. Odeio empolamento, erudição forçada ou preconceituosa e, porra, eu nasci provocando. Eu não quero provocar. Eu provoco. É instintivo. Procuro não controlar. É pior.

Você já escreveu sobre Geração zero zero, organizada por Nelson de Oliveira: críticos, teóricos, historiógrafos da literatura de um lado; do outro o escritor. Escreva minimamente sobre estas relações. 
Marcelo Benvenutti - Sinceramente prefiro qualquer crítica mal escrita ou negativa a nenhuma. Nenhuma é o fim. O fim dos leitores, da literatura e da própria crítica. Os teóricos e historiógrafos de hoje falam do passado. O que escrevo só vai ser passado no futuro. E eles também serão passado, portanto, ignoro.

Do ponto de vista da realimentação de sua escrita em fluxo contínuo, qual o papel da sua formação (em área aparentemente distante da literatura) - no seu modo de ver?

Marcelo Benvenutti - Nenhuma. A influência de me dedicar a outras carreiras, de contador, basicamente, para me sustentar, só influencia pelo fato de um escritor viver outros mundos e outras realidades. Me alimento dos ambientes, das pessoas, do convívio e de ouvir. O escritor enclausurado e ensimesmado pode até ser um gênio, mas pra mim não passa de um chato.

Os materiais não literários tornam-se literários?A escrita literária se constrói a partir do mundo? As esferas históricas, sociais, políticas e estéticas imbricamse?

Marcelo Benvenutti - Tudo, pra mim, é uma confusão, um sopão que vou deixando os ingredientes entrarem na minha mente e ficarem lá cozinhando, um pegando o sabor do outro, até que fiquem bem cozidos e comestíveis. Daí é só temperar e devorar. Da forma mais rápida possível.

A sua criação, ou o seu trabalho? Ou nada disso?

Marcelo Benvenutti - Óbvio que a literatura é um retrato da tua mente e de como ela enxerga o mundo. Ou simplesmente é um saudável delírio que tu conseguiu transformar em expressão artística. Pode ser tudo. Ou nada disso.

As relações entre a literatura e a política sempre se tornam objeto de questionamento. A política é importante para a literatura? Para a arte? Em que sentido? No seu caso, o caldo da pergunta fica ainda mais grosso: e religião onde entra?

Marcelo Benvenutti - Já ouvi muitos escritores dizerem que literatura não tem nada de político. Eu discordo. Tem. E não é porque um ou outros escreva explicitamente sobre política. É porque política envolve as relações sociais e quando tu escreve, bem ou mal, certo ou errado, tem uma visão de mundo, mesmo que seja uma não-visão, pois até o não-querer é um posicionamento. 
Então, um escritor dizer que não existe política no que escreve é cegueira do escritor. Ou canalhice.

Quanto à religião, mesmo questionando minha formação católica, não tento fugir dela. Fugir dela me jogaria contra. Ignorar seria uma bobagem, mas muitas vezes ignoro. Mas ela está ali. Faz parte da minha educação. Não posso, e nem quero, mudar.

Você toca Bukonski em sua literatura?

Marcelo Benvenutti - Toco e toco muitos outros instrumentos. Mas, infelizmente, Bukowski sofre por ser a referência mais próxima do leitor comum e dos críticos preguiçosos. Eu mesmo descobri Bukowski depois dos 30 anos quando me disseram que o que escrevia parecia com histórias do Bukowski. Não tenho culpa se o senso comum não consiga enxergar que pessoas, e escritores, mesmo distanciados por décadas ou séculos e locais e línguas diferentes tenham a mesma formação de ambiente. Bukowski é uma referência. Assim como muitos outros, assim como muito cinema e música. Não é o escritor que faz suas referências. Elas existem. Só.

Seus trabalhos literários foram traduzidos para outro idiom?.

Marcelo Benvenutti - Não. Gostaria que fossem para o espanhol. Gosto de ler e imaginar o que escrevo em espanhol, mesmo não sabendo escrever na língua. 


\section{ENTRE OS SEGREDOS DAS LEITURAS E A ESCRITA PÚBLICA}

Antonio Rodrigues Belon ${ }^{6}$ Bianca Estevam Veloso Ferreira ${ }^{7}$

Ana Paula Maia nasceu em Nova Iguaçu, no Rio de Janeiro, em 1977.

Publicou $O$ habitante das falhas subterrâneas (romance, 2003), A guerra dos bastardos (romance, 2007; Rat Kopilad, na edição Sérvia), Entre rinhas de cachorros e porcos abatidos (romance, 2009), Carvão animal (romance, 2011) e o primeiro folhetim pulp da internet, em 12 capítulos, além de contos em diversas antologias no Brasil e no exterior.

www.killing-travis.blogspot.com é localização dela na internet.

Um percurso do zero a uma vida como escritora, com fé em Deus, parece apontar para uma singularidade entre os contemporâneos. No fazer literário não vê a interferência da internet. Uma identidade sem amarras: "escrevo tudo o que preciso escrever".

As relações contraditórias com a escrita em dois aspectos: de um lado, a relação difícil com o assunto; na polarização, "a visão mais política da sociedade sobre tal tema, e suas possíveis implicações". A fé e o compromisso político fazem uma síntese? A onipresença dos animais em duas mãos: "bestializar o homem e humanizar o animal".

No caminho do reconhecimento não chegou a passar ainda pela fase do confortável. Quem escreve assiste a muitos filmes diversificadamente. Dos filmes que vê a escritora fala; sobre os livros que lê se cala.

Você já possui um relevante percurso pela literatura brasileira contemporânea, com quatro obras publicadas e participação em diversas antologias. Como analisa sua trajetória até agora e como planeja seus passos futuros?

Ana Paula Maia - Comecei do zero, como alguém que está diante de uma folha em branco. Não havia nenhuma perspectiva de uma vida como escritora. Eu não tinha amigos no meio literário, não freqüentava noites de autógrafos, não tinha quem pudesse me aconselhar. Mas tenho (fé) em Deus e ela faz a diferença. Posso dizer seguramente que a minha trajetória é feita de fé em

\footnotetext{
${ }_{7}^{6}$ Identificado na nota 1.

7 Aluna do Programa de Pós-Graduação, Mestrado em Letras, da Universidade Federal de Mato Grosso do Sul.
} 
Deus e coragem, afinal, a minha literatura não é assim a coisa mais agradável de se ler. Quando se deseja criar um conjunto literário que trate de temas como violência, trabalho braçal, pobreza e principalmente as relações humanas em seu aspecto mais sombrio, é preciso ser macho e ter boa pontaria. Nunca me acovardo diante de nada, nem da folha em branco, nem dos temas que escrevo.

Você se mantém ativa na internet, seja através do seu blog, twitter ou facebook, inclusive as suas obras Carvão Animal e Entre Rinhas de cachorros e porcos abatidos, já se encontram disponíveis para a venda em diversas livrarias digitais. Você considera a internet como um lugar propício para a produção literária? Acompanha algum site ou blog sobre literatura?

Ana Paula Maia - Não acompanho nenhum site ou blog com regularidade. A internet é um lugar propício para difundir a literatura: publicando textos ou fazendo propaganda de livros e autores. No mais, não vejo como ela pode interferir no fazer literário.

A idéia ou conceito de escritor que você tinha no início da sua carreira condiz com sua realidade ou com a realidade do mercado e do leitor? O que mudou nesse tempo?

Ana Paula Maia - Sou uma pessoa muito simples. Achava que escritor era um termo para alguém muito culto e que estava associado a um patamar distante de mim. Demorei para assumir a identidade de escritora. Eu nunca conheci um escritor pessoalmente até me tornar uma, quando ainda estava nos primeiros passos. Inicialmente eu não pensava em mercado ou leitor. Isso não existia no início. Tudo o que existia era uma grande angústia de como as coisas podiam acontecer e o que fazer. O que mudou é que hoje estou inserida num mercado e tenho alguns leitores. Escrevo com mais consciência, imaginando o que aquele texto pode causar. Porém, não tenho amarras para escrever...escrevo tudo o que preciso escrever.

Você já participou de diversas antologias, uma delas denomina-se 25 mulheres que estão fazendo a nova literatura brasileira, no entanto a sua literatura diverge do que pode ser chamada de "literatura feminina". Os cenários de suas histórias são sempre violentos, brutos, os homens possuem voz predominante em sua escrita. Qual a sua relação com esse universo? 
Ana Paula Maia - A melhor e a pior possível. Não é o meu universo, mas gosto de me imaginar nele. Por outro lado, escrevo sobre assuntos que me causam repulsa, indignação, medo e até horror. Dois aspectos são fundamentais quando escrevo. O primeiro é a relação difícil que tenho com o assunto e a outra é a visão mais política da sociedade sobre tal tema, e suas possíveis implicações. Dessa forma as relações humanas estão sempre bem pontuadas, pois é dessas relações que extraio a minha concepção dos assuntos que me repelem.

Outra característica relevante em suas histórias é a presença dos animais. Qual o peso dessas personagens em sua literatura?

Ana Paula Maia - Sempre que coloco algum animal na história, ele se torna muito importante para ela. No fim das contas, dentro do texto, eles estão praticamente em pé de igualdade com os homens, e isso me possibilita mostrar o contraponto que aparece nas histórias: bestializar o homem e humanizar o animal.

Antigamente as antologias tinham o papel de consagrar textos literários, na contemporaneidade elas desempenham o papel de consagrar os autores. Você foi incluída em diversas, concorrendo a vários prêmios e está sendo publicada em outros países, como o romance "Guerra dos Bastardos" que no ano passado foi lançado na Sérvia. Você ocupa uma posição confortável no mercado literário? Como se avalia profissionalmente? Você se considera um autora reconhecida?

Ana Paula Maia - Não ocupo um lugar confortável ainda e acho que isso leva tempo. Reconhecimento também leva tempo, mas sigo um dia após o outro no fazer literário. Não é possível ter pressa quando o assunto é literatura. A média de produção de um escritor é praticamente o tempo que ainda the resta de vida. Se eu chegar aos cem anos, imagina quanto ainda para escrever...(risos). Profissionalmente, eu quero sempre mais. E isso é bom, caso contrário, estagna. Mas eu passo mais tempo avaliando o projeto literário em que estou envolvida do que pensar na minha posição, profissionalmente, quero dizer. Prefiro ainda pensar só nos livros e deixar que as coisas sigam.

Segundo outras entrevistas, você diz absorver muitas influências cinematográficas, e além de utilizá-las como inspiração para seus trabalhos, 
também lançou trailers de duas de suas obras em cinemas, "A guerra dos bastardos" e "Entre rinhas de cachorros e porcos abatidos". Quais os últimos filmes que assistiu?

Ana Paula Maia - Aí, é difícil...uma lista comprida. Dos últimos filmes que mais me marcaram nos últimos tempos estão: Sonata de Outono (Bergman), 0 homem urso (Herzog), Distrito 9 (Neill Blomkamp) e o Planeta dos Macacos: a origem. É um gosto muito variado. Tem muito mais, mas paramos por aqui. Por fim, o que você está lendo? O que está escrevendo?

Ana Paula Maia - Aí é segredo...tudo segredo. 


\section{DA IMPORTÂNCIA DO SILÊNCIO: A ESCRITA DE DANIEL GALERA}

Antonio Rodrigues Belon ${ }^{8}$ Fabrina Martinez de Souza ${ }^{9}$

Daniel Galera nasceu na cidade de São Paulo; paulistano e paulista de 1979. Romancista, contista, tradutor, editor e músico. Na infância muda-se para Porto Alegre, no Rio Grande do Sul. Forma-se em publicidade e propaganda.

$\mathrm{Na}$ internet publica e edita blogs e sítios de 1996 a 2001. Três anos atua como colunista do Cardosonline (COL), um fanzine por e-mail. Em 1997 cria o sítio Proa da Palavra para a divulgação de textos literários inéditos. Em 2001 funda, com Daniel Pellizzari e Guilherme Pilla, Livros do Mal, uma editora para publicar novos autores. Ali, logo no começo, lança seu primeiro livro de contos, Dentes Guardados. O título está disponível em PDF em www.ranchocarne.org. Publica Até o Dia em que o Cão Morreu (romance, 2003), Mãos de Cavalo (romance, 2006), Cordilheira (romance, 2008) e Cachalote (graphic novel, 2010), escrita em pareceria com Rafael Coutinho.

A linguagem coloquial de Porto Alegre, dos jovens de classe média baixa, com os seus dramas cotidianos e a passagem para a maturidade, mistura violência e lirismo.

Daniel Galera trabalha como tradutor literário. Traduz autores da língua inglesa e publica, eventualmente, resenhas, ensaios e reportagens. Recebeu os Prêmios Machado de Assis (2008) e Jabuti (2009).

Formou seu público-leitor antes de sua estreia - oficial, convencional e impressa - como escritor. "É o caminho mais óbvio para o novo autor contemporâneo: iniciar publicando nos meios digitais, fazer alguma espécie de auto-edição, chamar atenção de editores" minimizando peculiaridades. Uma trajetória constituída pela ausência de planos e pelos improvisos. Um caminho em passo a passo, sempre orientado pelo desejo de se expressar pela escrita e mergulhar cada vez mais na literatura.

A compreensão da internet como um lugar apropriado para a discussão literária, mas não para a publicação de literatura. A preferência pelos livros

\footnotetext{
8 Identificado na nota 1.

9 Aluna do Programa de Pós-Graduação, Mestrado em Letras, da Universidade Federal de Mato Grosso do Sul.
} 
impressos ou digitais. "Para a poesia, creio que a internet é um pouco mais adequada", Daniel Galera registra.

Sobre a repercussão de sua literatura: diretamente para elogiar, para criticar raramente o confronto. As funções da literatura, entre a solidão e a interação, na perspectiva do individualismo: "A literatura já não possui tanto função revolucionária, social ou religiosa, ela vem se tornando uma forma de comunicação entre individualidades no mundo moderno, e portanto a interação do autor com o leitor ganha um aspecto historicamente novo. Gosto desse contato, porque a atividade da escrita é muito solitária. Aprecio essa solidão criativa, mas ela fica ainda mais interessante se existe o contraponto da interação com o leitor, e a internet e os eventos literários proporcionam isso."

As decisões do indivíduo no estabelecimento das fronteiras entre 0 público e o privado no compartilhamento entre a vida de verdade e a vida literária. Daniel Galera foi aluno e foi ministrante de oficinas literárias: entende o escrever como expressão, vocação e técnica. A idealização da escrita é nociva. A escrita como salvação não funciona para ele. O prazer de viver entre sacrifícios e sofrimentos alimenta as suas relações com a escrita literária. Uma protagonista - feminina (em Cordilheira) - não difere tanto assim em termos de linguagem.

"O silêncio, para mim, é uma das coisas mais importantes que existem" é a frase lapidar para quem, figura pública em razão da palavra escrita mudez portadora de muitos sons - entrega-se à vertigem da linguagem.

A irrelevância dos rótulos regionais, para Daniel Galera, uma idiossincrasia de leitor mais que de autor, articula explicitamente quem lê a quem escreve. Fala do papel pequeno das antologias no reconhecimento do autor. "Nunca depositarei na minha literatura o fardo de ser o meu sustento", como se separasse a comida da literatura.

O que lê o autor? Escritas e leituras em diálogo sempre: Verão de J.M. Coetzee, O livro de Praga - narrativas de amor e arte - de Sérgio Sant'Anna, os Ensaios, de Montaigne, Ulisses, de James Joyce e Guerra e Paz, de Liev Tolstói. 
Você tem um caminho peculiar pela literatura. Formou seu público-leitor antes da estreia (oficial) como escritor, criou seu próprio selo e hoje é publicado por uma das editoras mais importantes do país. Como analisa sua trajetória até agora e como planeja seus passos futuros?

Daniel Galera - Não creio que seja peculiar. É o caminho mais óbvio para o novo autor contemporâneo: iniciar publicando nos meios digitais, fazer alguma espécie de auto-edição, chamar atenção de editores. $O$ que pode ser peculiar é eu ter não apenas me autopublicado, mas criado um selo independente - a editora Livros do Mal - para publicar outros autores (a editora operou entre 2001 e 2004). Eu, Daniel Pellizzari e Joca Terron, entre outros, fizemos parte da primeira onda de autores que exploraram a internet dessa forma, e, portanto na época havia alguma peculiaridade nas nossas carreiras iniciantes. Mas hoje em dia tudo isso é bem comum. E não sou muito de analisar minha trajetória, porque nunca tive um plano definido quanto ao meu futuro como escritor. Fui improvisando, decidindo passo a passo, sempre motivado pelo desejo de me expressar pela escrita e me envolver cada vez mais com a literatura. É como ainda penso. Meu passo futuro agora é terminar meu próximo romance.

Você se mantém ativo na internet, seja através do seu site, Twitter ou Facebook. A internet é um lugar propício para a produção literária? Você acompanha algum site ou blog sobre literatura?

Daniel Galera - A internet é um lugar propício para a discussão literária, para a autodivulgação e para o estabelecimento de redes sociais baseadas em interesses comuns, literários no caso. Mas ela não é um lugar propício para a publicação de literatura. Os leitores não gostam muito de ler na internet. Todos preferem livros impressos ou digitais. Participo da internet como qualquer pessoa, mas penso no livro como formato ideal de publicação de ficção, ainda. Para a poesia, creio que a internet é um pouco mais adequada.

Desde o COL até Cachalote, você transitou por muitos sites ou blogs ora falando da sua trajetória profissional ora pessoal. Como é a sua relação com seu público-leitor? Que tipo de resposta você recebe? O público que o 
acompanha desde o COL lê suas obras de maneira diferente? Como você enxerga esse leitor especificamente?

Daniel Galera - A verdade é que a maioria das pessoas que se comunicam diretamente comigo o fazem para elogiar. Quem quer criticar raramente toma a iniciativa de confrontar o autor. Se quero encontrar críticas ao meu trabalho na rede, preciso ir atrás delas - e as encontro. Mas a relação com o leitor é cordial e baseada no elogio. Isso não quer dizer que seja rasa ou inútil. Além do componente óbvio de vaidade envolvido, muitos leitores oferecem interpretações e perguntas interessantes sobre o meu trabalho, que por vezes me fazem rever minhas convicções ou ideias. A literatura já não possui tanto função revolucionária, social ou religiosa, ela vem se tornando uma forma de comunicação entre individualidades no mundo moderno, e portanto a interação do autor com o leitor ganha um aspecto historicamente novo. Gosto desse contato, porque a atividade da escrita é muito solitária. Aprecio essa solidão criativa, mas ela fica ainda mais interessante se existe o contraponto da interação com o leitor, e a internet e os eventos literários proporcionam isso. Só é preciso saber dosar bem essa interação com o público, pois ela pode tomar tempo e energia da escrita. Sei que existe esse perigo e procuro me manter sempre consciente disso.

Há muitas referências pessoais e piadas internas em sua obra. Quais são as suas fronteiras de público e privado? Aliás, o que é público e privado para você?

Daniel Galera - A fronteira entre o público e o privado na arte e na vida cotidiana só pode ser decidida pelo indivíduo e ele possui soberania para decidi-la e impô-la, na minha visão das coisas. Essa decisão deve ser respeitada. Procuro respeitar a dos outros e espero que respeitem a minha. Tudo que eu colocar numa rede social ou num livro terá sido declarado público. O que eu decido preservar é privado, e deve ser tratado como tal. Dito isso, há uma diferença enorme entre público/privado e biográfico/fictício, são questões bem diferentes. É ingênuo quem acredita ser capaz de traçar uma linha clara entre o que é autobiográfico e fictício numa obra de ficção - mesmo o autor não está totalmente capacitado a isso. A sociedade moderna valoriza demais a 
figura do autor em detrimento da obra desse autor, e uma das reações naturais do autor a isso é confundir de propósito as coisas, como se quisesse punir a pretensão e a ingenuidade do leitor. É um traço importante da literatura contemporânea, como se pode ver em livros como, digamos, Verão de J.M. Coetzee.

Como você administra a quantidade de informações disponíveis sobre sua vida e os possíveis impactos que isso pode ter em seus leitores?

Daniel Galera - Regulando o que compartilho em sites, entrevistas e nas redes sociais. É só o que se pode fazer. Compartilho uma parte bem pequena da minha vida, na verdade. Eu sei que isso que está disponível na internet é uma faceta pequena e um pouco distorcida de quem eu realmente sou. E sei que eu próprio não conheço verdadeiramente a vida de ninguém com base no que leio na internet, porque todos nós construímos narrativas de identidade algo fictícias nos meios digitais. Escolhemos o que exibir e o que esconder, modificamos e deformamos a realidade sem nenhum pudor, construindo personagens para nós mesmos. Quem pensa diferente está enganado. Me deparo constantemente com julgamentos sobre mim que foram feitos com base em meus livros e na minha persona virtual e que sei que estão completamente equivocados. Mas não se pode fazer nada. Tento ser comedido e honesto na minha presença pública, mas certo um grau de construção fictícia é inevitável.

Você já foi aluno de oficinas literárias e ministrou tantas outras. O ofício da escrita pode ser ensinado? A ideia da escrita como resignação ou salvação é romântica, verdadeira ou idealizada?

Daniel Galera - Escrever depende de necessidade de expressão, vocação e técnica. Uma oficina ajuda na técnica, e às vezes pode despertar a pessoa para a presença ou não dos dois outros requisitos. E acho que a escrita pode significar muitas coisas diferentes para os autores, entre elas, sim, uma espécie de salvação. Não é o meu caso. Eu viveria razoavelmente bem sem escrever, não precisaria ser salvo. Mas acho que seria muito mais solitário sem a escrita. A idealização nociva da escrita está na noção de que a literatura existe acima dos homens, que paira com seu valor intocável sobre a sociedade 
e os indivíduos. Mas a literatura é uma coisa mundana, ela tem o exato valor de sua relevância pras pessoas num determinado momento.

A ideia ou conceito de escritor que você tinha no início da sua carreira condiz com sua realidade ou com a realidade do mercado? O que mudou nesse tempo?

Daniel Galera - Eu tinha tão pouco ideia do que era ser escritor antes de começar a publicar, e tão pouca ambição, que não teria muito como me frustrar. Mas a literatura tem tornado minha vida algo muito interessante e prazeroso de viver (incluídos aí os sacrifícios e sofrimentos), então acho que minhas expectativas, sejam quais fossem, foram superadas.

Em Cordilheira, pela primeira vez, você escreveu uma protagonista feminina. $\mathrm{O}$ que isso mudou no processo de elaboração do livro?

Daniel Galera - Não acho que mudou muita coisa. É difícil ter que imaginar o ponto de vista de uma mulher ao longo de meses para a construção de todo um romance sob essa perspectiva, mas ao mesmo tempo não era nada tão misterioso ou ousado quanto eu imaginava antes de começar a escrevê-lo de fato. É como escrever um livro inteiro do ponto de vista de um homem muito idoso, ou uma criança muito pequena, ou de um animal, ou do vento -- algo que exige um ajuste da imaginação pra se colocar no lugar dessa outra experiência. Exige pesquisa e despudor na hora de se colocar no lugar da personagem. Mas minha conclusão é que as mulheres não são tão diferentes dos homens quanto se gosta de acreditar, do ponto de vista da linguagem literária. Tentei reforçar isso na construção da Anita -- ela tem características e uma linguagem que à primeira vista podem parecer um tanto antifemininas, mas estou convencido de que ela é uma jovem mulher moderna verossímil, à parte sua obsessão um pouco doentia em ter um filho a qualquer custo, que foi um exagero calculado para reforçar o significado da história.

O silêncio é uma constante em seus livros. Qual a importância do silêncio na sua vida? 
Daniel Galera - O silêncio, para mim, é uma das coisas mais importantes que existem. É o estado das coisas perfeitas, o espaço ideal da criatividade, o recanto mais propício ao espírito.

Em entrevista, você afirmou que não acredita em literatura gaúcha, brasileira ou universal, apenas em literatura. Que literatura é essa?

Daniel Galera - Só acho que rótulos regionais são irrelevantes ou, nos casos especiais, pouco relevantes. São recortes que pouco acrescentam para autores e leitores -- podem até ser nocivos, quando estabelecem critérios do que é mais ou menos literário para um autor de um determinado lugar etc. É como pensar que o autor brasileiro precisa tratar da realidade da favela ou da corrupção para ser um bom autor. Ele pode tratar disso, mas há incontáveis outras abordagens possíveis para um bom autor, que podem ficar obscurecidas pelos cacoetes e imperativos regionais. Não acho que sirva pra muita coisa. Sei que é idiossincrático, mas é assim que vejo a coisa como leitor, e portanto também como autor.

Antigamente as antologias tinham o papel de consagrar textos literários, na contemporaneidade elas desempenham o papel de consagrar os autores. Você foi incluído em diversas, concorreu a prêmios e é publicado em outros países. Você ocupa uma posição confortável no mercado literário? Como se avalia profissionalmente? Você se considera um autor reconhecido?

Daniel Galera - Me considero um autor reconhecido, mas não tanto por antologias ou prêmios -- na verdade, não participei de muitas, nem ganhei muitos prêmios -- foram só dois, e um deles, o Jabuti, foi de terceiro lugar. $O$ reconhecimento que me estimula é o dos meus editores, dos meus amigos, da minha familia, e sobretudo dos leitores. Me sinto muito confortável na Companhia das Letras, eles apostam muito mim, e também esperam muito de mim. Quer dizer, sinto que tenho condições ideais de seguir escrevendo. Isso não quer dizer que me sinta confortável, pois do ponto de vista criativo não resolve nada: cada novo livro segue exigindo o mesmo esforço e oferece a mesma insegurança, a mesma incerteza de onde isso tudo vai dar. Preciso escrever bem, preciso colocar paixão e esforço nisso de novo e de novo, 
sempre que me aventurar a escrever um novo conto ou romance. Então nunca fica exatamente confortável. Mas do ponto de vista prático, de ter um público leitor e uma editora me apoiando, disso não posso reclamar, tenho sorte e sei valorizar isso. Vendo bem para a média de um jovem autor nacional, mas não escrevo tentando otimizar o desempenho comercial dos meus livros. Nunca depositarei na minha literatura o fardo de ser o meu sustento.

Por fim, o que você está lendo? O que está escrevendo?

Daniel Galera - Estou lendo o último do Sérgio Sant'Anna e os ensaios do Montaigne, e nesse verão pretendo encarar dois livrões que ainda não li: o Ulisses do Joyce e o Guerra e Paz do Tolstói. Gosto de intercalar a ficção com livros de reportagem e ciência, sobretudo neurociência e física, que me fascinam. E estou escrevendo um novo romance intitulado Barba ensopada de sangue, ainda sem previsão de término. 